\title{
Assessment of Hand Motor Function in a Non-human Primate Model of Ischemic Stroke
}

\author{
Jinyoung Won ${ }^{1 \dagger}$, Kyung Sik Yi ${ }^{2 \dagger}$, Chi-Hoon $\mathrm{Choi}^{2 \dagger}$, Chang-Yeop Jeon ${ }^{1 \dagger}$, Jincheol Seo ${ }^{1}$, Keonwoo Kim ${ }^{1,3}$, \\ Hyeon-Gu Yeo ${ }^{1,4}$, Junghyung Park ${ }^{1}$, Yu Gyeong Kim ${ }^{1,4}$, Yeung Bae Jin ${ }^{1}$, Bon-Sang Koo ${ }^{1}$, \\ Kyung Seob Lim ${ }^{5}$, Sangil Lee ${ }^{1}$, Ki Jin Kim ${ }^{1}$, Won Seok Choi ${ }^{1}$, Sung-Hyun Park ${ }^{1}$, Young-Hyun Kim ${ }^{1,4}$, \\ Jae-Won Huh ${ }^{1,4}$, Sang-Rae Lee ${ }^{1,4}$, Sang-Hoon Cha ${ }^{2 *}$ and Youngjeon Lee ${ }^{1,4 *}$ \\ ${ }^{1}$ National Primate Research Center, Korea Research Institute of Bioscience and Biotechnology (KRIBB), Cheongju 28116, \\ ${ }^{2}$ Department of Radiology, Chungbuk National University Hospital, Cheongju 28644, ${ }^{3}$ School of Life Sciences, \\ BK21 Plus KNU Creative BioResearch Group, Kyungpook National University, Daegu 41566, \\ ${ }^{4}$ Department of Functional Genomics, KRIBB School of Bioscience, Korea University of Science and Technology, \\ Daejeon 34113, ${ }^{5}$ Futuristic Animal Resource \& Research Center, KRIBB, Cheongju 28116, Korea
}

Ischemic stroke results from arterial occlusion and can cause irreversible brain injury. A non-human primate (NHP) model of ischemic stroke was previously developed to investigate its pathophysiology and for efficacy testing of therapeutic candidates; however, fine motor impairment remains to be well-characterized. We evaluated hand motor function in a cynomolgus monkey model of ischemic stroke. Endovascular transient middle cerebral artery occlusion (MCAO) with an angiographic microcatheter induced cerebral infarction. In vivo magnetic resonance imaging mapped and measured the ischemia-induced infarct lesion. In vivo diffusion tensor imaging (DTI) of the stroke lesion to assess the neuroplastic changes and fiber tractography demonstrated three-dimensional patterns in the corticospinal tract 12 weeks after MCAO. The hand dexterity task (HDT) was used to evaluate fine motor movement of upper extremity digits. The HDT was modified for a home cage-based training system, instead of conventional chair restraint training. The lesion was localized in the middle cerebral artery territory, including the sensorimotor cortex. Maximum infarct volume was exhibited over the first week after MCAO, which progressively inhibited ischemic core expansion, manifested by enhanced functional recovery of the affected hand over 12 weeks after MCAO. The total performance time decreased with increasing success rate for both hands on the HDT. Compensatory strategies and retrieval failure improved in the chronic phase after stroke. Our findings demonstrate the recovery of fine motor skill after stroke, and outline the behavioral characteristics and features of functional disorder of NHP stroke model, providing a basis for assessing hand motor function after stroke.

Key words: Dexterity, Diffusion tensor imaging, Functional recovery, Hand function, Ischemic stroke, Magnetic resonance imaging

\footnotetext{
Submitted June 11,2020, Revised August 7,2020,

Accepted August 24, 2020

* To whom correspondence should be addressed.

Youngjeon Lee, TEL: 82-43-240-6316, FAX: 82-43-240-6309

e-mail:neurosci@kribb.re.kr

Sang-Hoon Cha, TEL: 82-43-269-6473, FAX: 82-43-269-6479

e-mail:shcha@chungbuk.ac.kr

These authors contributed equally to this work.
}

\section{INTRODUCTION}

Stroke is the most common cause of adult death resulting from cardiovascular disease [1]. Cerebral ischemia is caused by restricted blood flow to the brain [2], and accounts for approximately $88 \%$ of all stroke cases [3]. Most ischemic strokes occur in the region of the middle cerebral artery (MCA) and lead to irreversible brain injury [4].

Stroke has a significant impact on the activities of daily living
Copyright $\odot$ Experimental Neurobiology 2020. www.enjournal.org
This is an Open Access article distributed under the terms of the Creative Commons Attribution Non-Commercial License (http://creativecommons.org/licenses/by-nc/4.0) which permits unrestricted non-commercial use, distribution, and reproduction in any medium, provided the original work is properly cited. 
(ADLs) in patients with stroke [5]. Indeed, the presence of neurological disorder presenting as ipsilateral hemiparesis significantly affects ADLs in these patients, and ADL performance is predominantly related to upper extremity motor function. A recent study reported that upper extremity dysfunction is associated with several ADL limitations in patients with upper motor neuron disorder after stroke [6,7]. In particular, hand motor impairments diminish movement capacity and coordination in stroke patients, which is consistent with animal studies [8]. Over $80 \%$ of stroke patients with neurological disorder experience a loss of voluntary movement and mobility in the upper extremities [9].

Animal models of stroke have been used to investigate the impact of cerebral ischemia on functional motor function [10]. However, there are limitations in the translation of animal model studies to clinical studies due to the different characteristics between human stroke patients and animal models. While there are similarities in the general structure of neurological systems in various mammals, the motor systems and fine motor control are most similar between humans and non-human primates (NHPs) [11-13]. The development of the corticospinal tract and manual dexterity is related in rodents, NHPs, and humans' [14]. Despite requiring a complicated procedure, the NHP stroke model is valuable and frequently utilized due to its similarity to human ischemic stroke [15]. The endovascular transient middle cerebral artery occlusion (MCAO) method is widely used to create NHP models of ischemic stroke [16]. However, a few studies have assessed motor skills in the MCAO-induced NHP stroke model. NHP stroke models displayed contralateral motor deficits in manual dexterity and grip strength $[17,18]$. McEntire et al. demonstrated impaired dexterity in African green monkey stroke models using the object retrieval task with a barrier-detour [19]. Moore et al. reported that the dexterity of the affected hand recovered to the baseline level using the hand dexterity task (HDT) in the rhesus monkey stroke models induced by cortical injury [20].

In the present study, we attempted to generate an NHP stroke model using an endovascular transient MCAO method, and evaluated hand dexterity impairment by a modified HDT that was designed for a home cage-based training system. Specific features of the NHP stroke model were demonstrated by assessing infarct lesions, diffusion tensor imaging (DTI) based fiber tractography, neurologic function, and behavioral changes, including fine motor function of the hand. Furthermore, lesion localization of the sensorimotor cortex was confirmed by assessing the macaque Paxinos atlas. Our findings have clinical applications, especially given the striking similarity between NHPs and humans.

\section{MATERIALS AND METHODS}

\section{Animals}

We used three adult (12-year-old) female cynomolgus macaques (Macaca fascicularis), which were obtained from Suzhou Xishan Zhongke Laboratory Animal Co. (Suzhou, China) and maintained in individual indoor cages at the National Primate Research Center (NPRC) in the Korea Research Institute of Bioscience and Biotechnology (KRIBB), as described previously [21, 22]. Animal was fed commercial monkey chow (Harlan, USA), supplemented with various fruits and water ad libitum. The controlled environmental conditions had a temperature of $24 \pm 2^{\circ} \mathrm{C}$, a relative humidity of $50 \pm 5 \%$, and a 12 -h light/dark cycle. All procedures were approved by the KRIBB Institutional Animal Care and Use Committee (Approval No. KRIBB-AEC-17080). Experimental procedures were performed in accordance with national guidelines and complying with the Guide for the Care and Use of Laboratory Animals. All animals were monitored minimally 2 times daily and were provided appropriate veterinary care by trained personnel. The health of animals was monitored by the attending veterinarian consistent with the recommendations of the Weatherall Report. Animal health monitoring was performed by microbiological tests including B virus, simian retrovirus (SRV), simian immunodeficiency virus (SIV), simian virus 40 (SV40), and simian T-cell lymphotropic virus (STLV) at once a year, as described previously [23]. In this study, hand motor function was assessed by using positive reinforcement training, and no animals were sacrificed. All animals were returned to their home cage at the end of the study.

\section{Experimental design}

The in vivo experimental study is shown in Fig. 1A. Baseline magnetic resonance imaging (MRI) was performed 8 days before $\mathrm{MCAO}$ to acquire the baseline image for comparison with postocclusion and reperfusion images. Follow-up MRI was performed to measure the infarct volume. Hand motor function was assessed using behavioral analysis. Among several NHP stroke models induced by MCAO, only one (Monkey A) showed that the hand motor function returned to baseline levels at 12 weeks. In this study, Monkey A has been used to investigate the localization of ischemic lesions, the reorganization of the white matter fiber and the functional changes in grip strategies.

\section{Transient ischemic stroke model and MRI}

The transient endovascular MCAO technique was applied as in our previous study $[24,25]$. An endovascular occlude was advanced over micro-guidewire (Synchro 14, Boston Scientific, Fremont, $\mathrm{CA}$ ) and wedged in the distal M1 or superior M2 division 
A

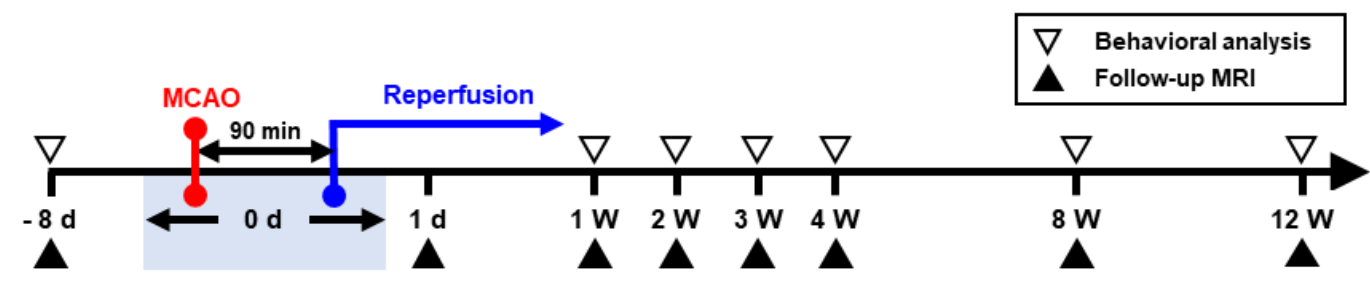

B
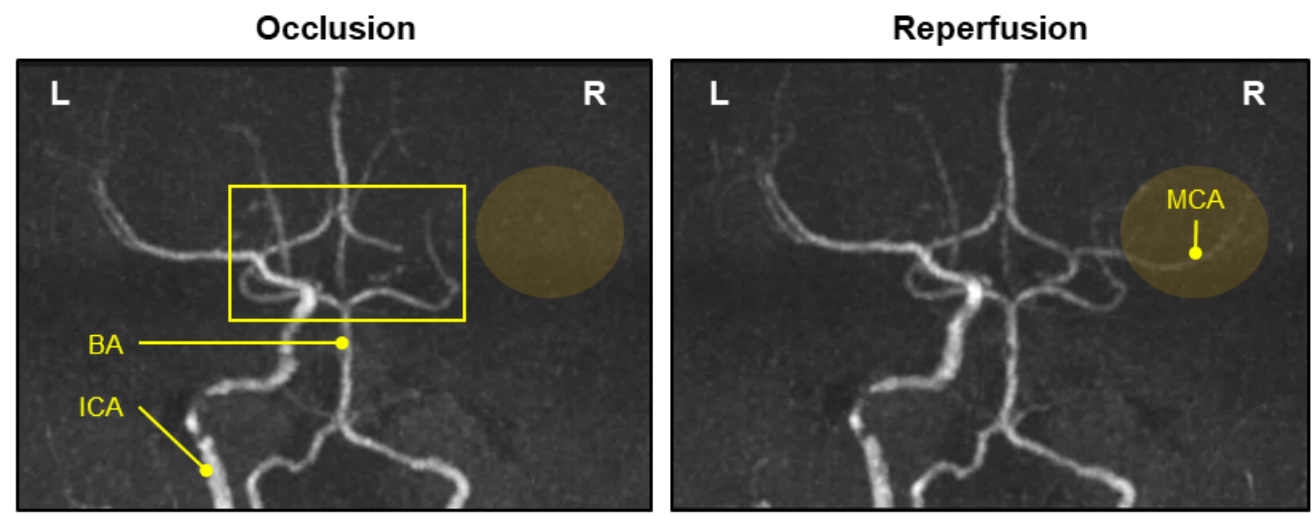

C

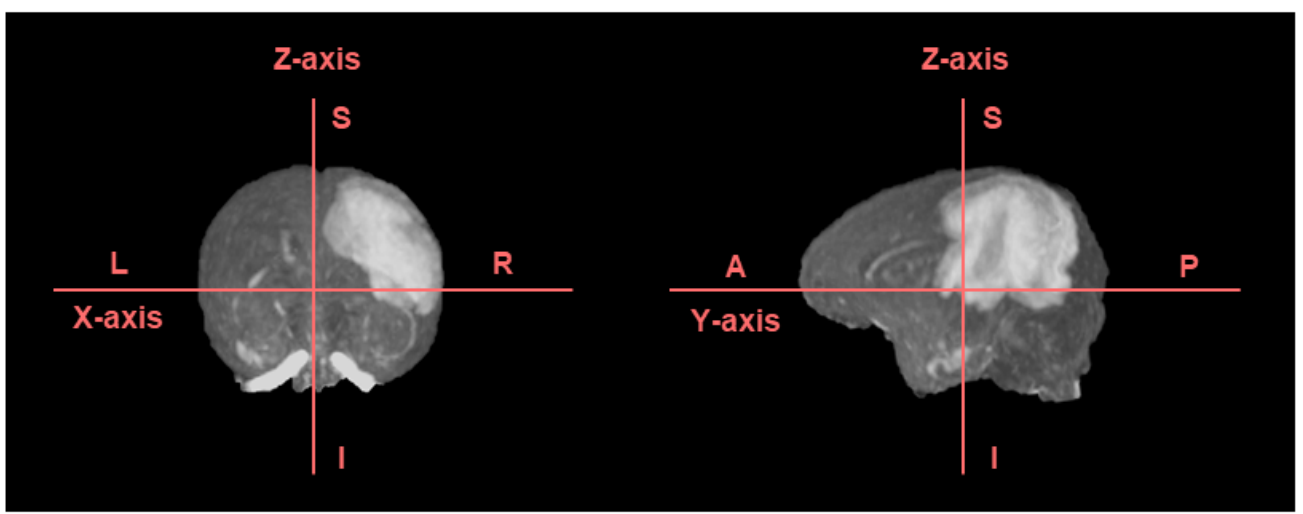

Fig. 1. Schematic presentation of the experimental design and magnetic resonance-based assessment for assessing the post stroke outcome. (A) The in vivo experimental study followed this scheme. (B) Magnetic resonance (MR) angiography of non-human primate models of focal cerebral ischemia. The occlusion and reperfusion of the middle cerebral artery (MCA) were confirmed using MR angiography. Left: the yellow rectangle indicates the circle of Willis located at the base of the brain. Right: MCA blood flow can be observed during reperfusion. (C) Representative 3D maximum intensity projection views of fluid-attenuated inversion recovery (FLAIR) images of the ischemic lesion $24 \mathrm{~h}$ after reperfusion. BA, basilar artery; ICA, internal carotid artery; MCA, middle cerebral artery; L, left; R, right; P, posterior; A, anterior; S, superior; I, inferior.

branch of the right MCA under double fluoroscopic roadmap images. Contrast media (Iversense 240, Accuzen, Seoul, Korea) was injected via a microcatheter, and flow arrest/stasis of the contrast media in the distal vasculature was monitored (Fig. 1B). Transient occlusion of the MCA was maintained for 90 min. immediately after the $90 \mathrm{~min}$ MCA occlusion, the animal was transported to the 3.0-T MRI scanner (Achieva 3.0 T, Philips Medical Systems, Best, Netherlands) with a 32-channel head coil. Three-dimensional (3D) sagittal T1-weighted images were acquired using a Turbo Field
Echo sequence. Fluid-attenuated inversion recovery (FLAIR) imaging was performed to determine the infarct size and lesion location after MCAO (Fig. 1C). Details of MRI protocols were same as the previous report [24].

\section{Diffusion MRI processing and diffusion tensor tractography}

All the scans were acquired by 128-direction DTI scanning and three different voxel sizes $\left(0.94 \times 0.94 \times 2.3 \mathrm{~mm}^{3}\right)$. The $\mathrm{dcm} 2$ nii was used to convert the NIfTI file from the DICOM file. The con- 
verted NIfTI data were preprocessed using FSL, and maps of the diffusion metrics, including fractional anisotropy (FA) and mean diffusivity (MD), were obtained. The region of interest (ROI) was defined on the structural T1-weighted MPRAGE images that underwent affine registration by FSL. FA and MD values were extracted from the ROIs placed within the corpus callosum (CC), and the right and left corticospinal tract (CST). Fiber tracking was performed using the fiber assignment by a continuous tracking (FACT) algorithm with an angle threshold of 35 degrees. The CST fiber tract was identified using multiple ROIs at different cervical levels. For the fiber tractography, CST segmentation was based on the multi ROI using the TrackVis software program (http://www. trackvis.org) and DTI fiber tracking was performed with a 35 degree threshold.

\section{Localization of cerebral ischemic infarct lesion}

Lesion localization was determined and visualized using FLAIR imaging and T1-weighted imaging at different time points after MCAO. The sagittal 3D FLAIR imaging data that were acquired by merging images at different time points showed the rostral-caudal extents of infarction. All the coronal images for lesion localization were selected from first appearance of infarct lesion at the rostral aspect of the central sulcus, past the region of the infarct core to its disappearance near the lunate sulcus. Representative coronal images through the infarct lesion were illustrated and regions of interest (ROIs) for analysis of cortical lesion location were outlined using the Paxinos Macaque Atlas illustration [26].

\section{Infarct volume measurement}

All MR data sets were transferred from the MR scanner to a personal desktop (Intel, Xeon, CPU E5-2620 v2). After data acquisition, whole-head FLAIR images were consistently cropped by box dimensions ( $\mathrm{x}=79.50 \mathrm{~mm}, \mathrm{y}=129.75 \mathrm{~mm}, \mathrm{z}=78.96 \mathrm{~mm}$ ) for further analysis. ROIs were measured with IRW v4.2 software (Siemens Healthcare, PA, US). The following formula was used to calculate the infarct volume: Infarct volume $(\%)=$ infarction $\left(\mathrm{mm}^{3}\right)$ / whole brain $\left(\mathrm{mm}^{3}\right) \times 100$ without a template volume. ROIs were automatically determined using equivalent thresholds to retain experimental objectivity including whole brain (38.0/251.0), infarct area (81.0/251.0), and window level (-1.6/268.6). The ROIs based on FLAIR images were indicated in representative images focused on slice 315/512 coronal sections, axial FOV $=12.98 \times 19.47$ $\mathrm{cm}$, coronal FOV $=13 \times 19.47 \mathrm{~cm}$, sagittal FOV $=13 \times 19.47 \mathrm{~cm}$, and scale $=1.15$. Four ROIs were selected for the whole brain (RGB: 0.255.0), infarct lesion (RGB: 255.0.0), brain template (RGB: 0.204.204), and infarction template (RGB: 255.0.255). The mean, standard deviation, min value, and max value were also automati- cally calculated using IRW with the exception of the template.

\section{Hand dexterity task}

The HDT was used to evaluate fine motor functions of the hand and digits, as described in previous rhesus monkey studies by Moore et al [27]. The HDT used in this study was slightly modified, whereby the testing apparatus was designed for a cage-based training system. The testing apparatus consisted of three components, including (1) a transparent acrylic case, (2) a transparent acrylic door, and (3) a HDT board (Fig. 2A). The front door of stainless steel home cage could be replaced by the acrylic door combined with acrylic case and the HDT board (Fig. 2B). The level of hand motor deficit was determined according to the latency to retrieve a reward. The HDT procedure for measuring the latency is shown in Fig. 3. Tracker video analysis for measuring the latency was conducted using the video analysis program by Tracker Video

A
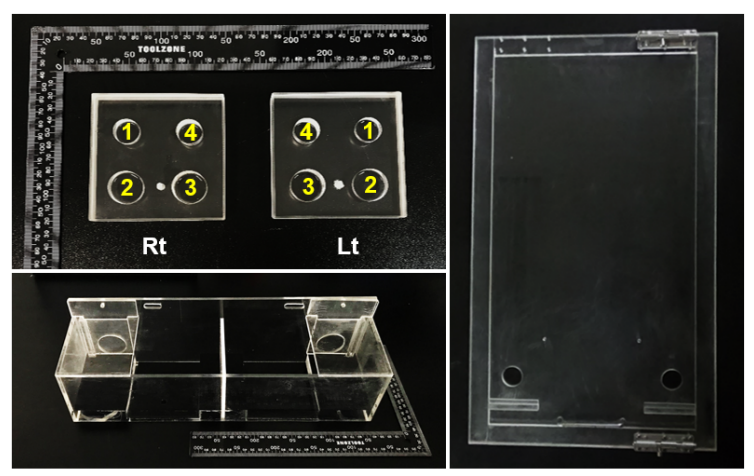

B

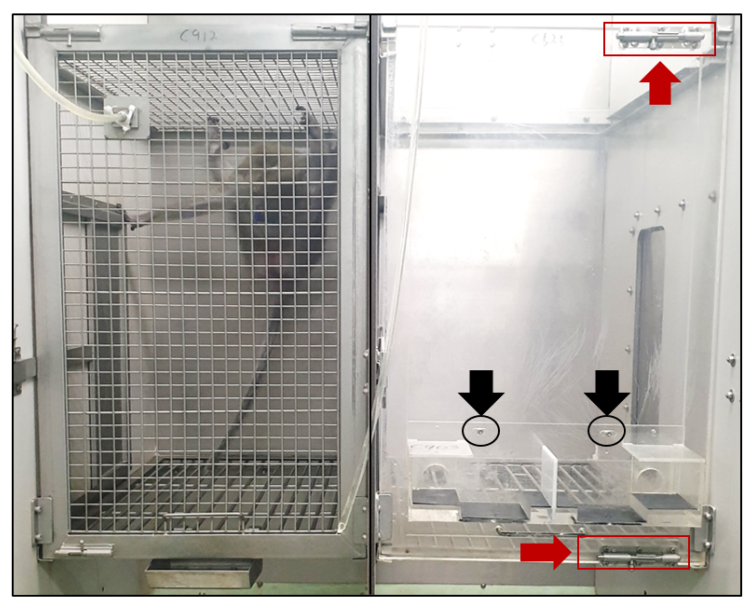

Fig. 2. The testing apparatus used to assess fine motor function of the hand in the NHP model. (A) The testing apparatus consisted of transparent acrylic case, transparent acrylic door, and HDT board. Top view of the HDT board (top-left panel). (B) The acrylic case combined with the HDT board was attached to the front panel of acrylic door by the hooks (black arrow in right panel). The acrylic door was connected to the home cage by the locks (red arrow in right panel). Rt, right; Lt, left. 

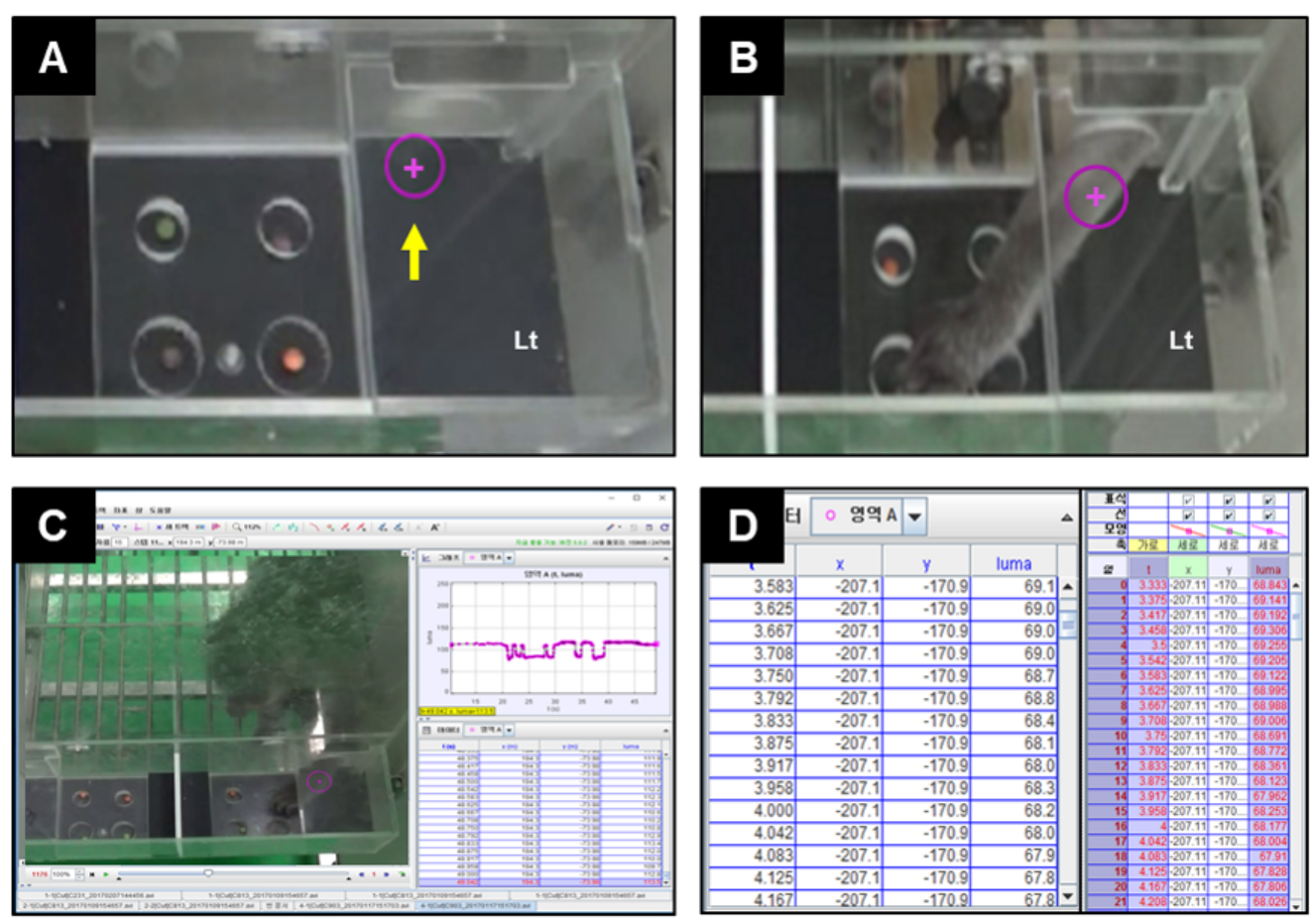

Fig. 3. Schematic representation of the HDT procedure. (A) The arrow indicates the RGB region. (B) An RGB region track measures the mean lightness of target and compares the color differences between two specimens, the bottom plate of the HDT and the forelimb of the monkey. (C, D) Representative images of the tracker video analysis of the HDT using the video analysis program by Tracker Video Analysis and Modelling Tool.
Analysis and Modelling Tool 4.87 (https://physlets.org/tracker/).

The animals were trained to retrieve $190 \mathrm{mg}$ pellets (Fruit Crunchies, Bio Serv, USA) from four wells of various depths and diameters located in a tray on the left or right side of the apparatus [28]. The four wells had the following characteristics: Well 1=narrow and shallow, Well 2=wide and shallow, Well $3=$ wide and deep, Well $4=$ narrow and deep; diameter: narrow $=1.9 \mathrm{~cm}$, wide $=2.5 \mathrm{~cm}$; depth: shallow $=0.95 \mathrm{~cm}$, deep $=1.6 \mathrm{~cm}$. A baseline test consisting of four trials for each of the four wells, for a total of eight trials for each hand, was conducted 1 week before the MCAO procedure. After MCAO, a total of four trials for the affected and non-affected hands were conducted once per week for 12 weeks. The score was defined by the execution time between the first pass through the entrance and the moment the hand left the HDT instrument with the reward. The execution time of each trial was limited to $2 \mathrm{~min}$ and the latency cut-off time was $15 \mathrm{~s}$.

Hand dominance was also determined using the HDT. The dominant hand was the hand that exhibited superior manual dexterity, defined as follows:

Hand dominance $=(\mathrm{L}-\mathrm{R}) /(\mathrm{L}+\mathrm{R})$

The number of times the left hand $(\mathrm{L})$ was used as the dominant hand minus the number of times the right hand $(\mathrm{R})$ was used, divided by the total number of hand uses [29]. Negative and positive hand dominance reflect left and right handedness, respectively.

\section{Statistical analysis}

Statistical analyses were performed using SPSS 18.0 (SPSS Inc., Chicago, IL, USA). Data are represented as the mean \pm SD or standard error of the mean. The significance of ischemic infarct volume change on MRI was assessed by a repeated measure ANOVA with a post hoc Tukey's test. A p-value of $<0.05$ was considered statistically significant.

\section{RESULTS}

\section{Amelioration of brain damage after transient MCAO}

3D axial and coronal FLAIR imaging obtained during follow-up was used to determine the longitudinal changes in MCAO territory infarct lesion (Fig. 4A). The ischemic lesions were observed in the MCA territory across the distal M1 and the superior M2 division branch. Notably, the substantial infarct size exhibited sustained effects of transient cerebral ischemia induced by MCAO at 1 week after reperfusion. Reduced infarct size was observed during the post-stroke recovery period. Total infarct volume was measured on FLAIR images (Fig. 4B). Maximal expansion of the ischemic lesion reached maximal expansion at 1 day after MCAO and ischemic injury was sustained at 1 week after MCAO. Total infarct volume was significantly reduced at $4 \sim 12$ weeks compared to that at 1 day and 1 week after MCAO. 

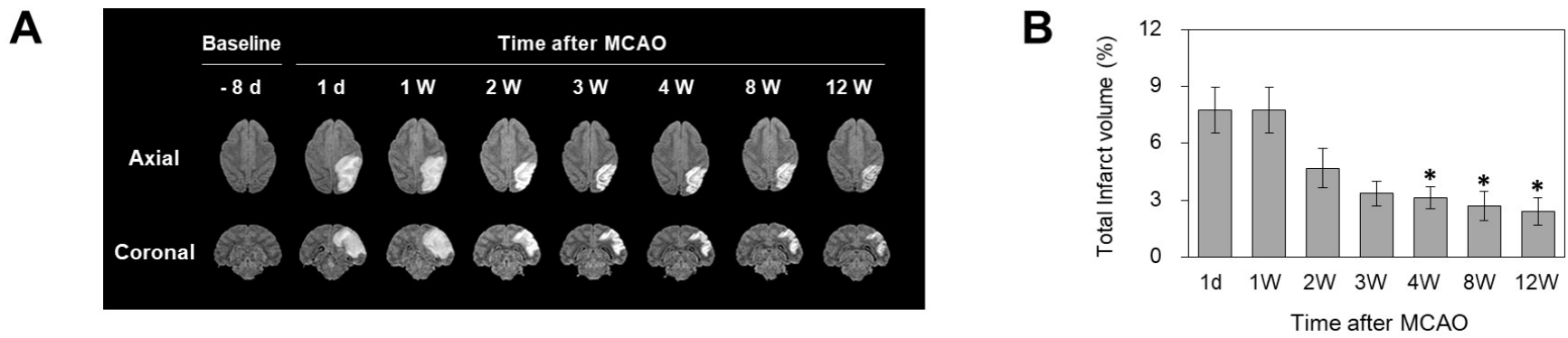

Fig. 4. Measurement of cerebral ischemic infarct lesion. (A) FLAIR MR follow-up was performed at 1 day, 1, 2, 3, 4, 8, and 12 weeks after MCAO. (B) Total infarct volume was measured using FLAIR imaging. Data are represented as the mean $\pm S D, n=3 .{ }^{*} p<0.05 v s$. $1 \mathrm{~d}$ and $1 \mathrm{~W}$.

\section{Localization of ischemic lesions in the NHP stroke model}

MR imaging was used to quantitatively assess the lesion localization. Following an ischemic attack caused by an arterial occlusion, cerebral infarction occurred in the MCA territory. The boundaries of the infarcted regions demonstrating the change of lesion location was indicated by red area on each coronal MR imaging and illustration (Fig. 5). Infarct lesion included the parietal cortex (somatosensory cortex and posterior parietal cortex), basal ganglia (putamen, caudate nucleus), and white matter. However, ischemic injury was not found in the premotor cortex and primary motor cortex during the post-stroke period. In the first week following MCAO, the infarct lesion was observed from near the central sulcus, past the region of somatosensory cortex to the posterior parietal cortex. However, the infarct lesion was not detected from 3 to 12 weeks after MCAO on the anterior aspect of the coronal section. Persistence of ischemic infarct lesion after MCAO is summarized in Table 1. The infarct lesion in primary somatosensory cortex and basal ganglia including putamen and caudate nucleus was exhibited during 1 week after MCAO. However, ischemic injury in putamen was not exhibited at 1 day but 1 week after MCAO due to expansion of the infarct lesion. The infarct lesion in secondary somatosensory cortex was revealed during 2 weeks, whereas ischemic injury persisted in posterior parietal cortex and white matter.

\section{Pre-operative assessment of hand function}

Pre-operative mean time to retrieve rewards from each well on the HDT was recorded during the baseline assessment (Fig. 6A). Hand dexterity differed between the shallow wells and deep wells. The latency for the deep wells was longer than that for the shallow wells. However, there was no difference in the motor function of each hand between these wells. These results indicated that the HDT with shallow wells is a simple and low-level task, whereas the deep wells require high-level manual dexterity.

During pre-operative training, the dominant hand that exhibited greater efficiency when performing a manual dexterity task was determined using the HDT. The laterality of hand dominance was assessed by comparing the mean time to perform the HDT between left and right hands. The individual hand dominance from three animals was indicated in Fig. 6B. Hand dominance was particularly evident for Well 3. A longer latency was exhibited by the right hand, which suggested left handedness.

\section{Longitudinal assessment of fine motor recovery in the af- fected hand after MCAO}

HDT performance improved over the 12 weeks following MCAO (Fig. 6C). When the non-affected hand was used to assist the affected hand, the latency cut-off time was $15 \mathrm{~s}$. During the first 4 weeks after MCAO, an increased mean time to retrieve a reward was observed in all four wells for the affected hand. Hand motor deficits were observed $<4$ weeks after MCAO in well $1 \sim 4$ and then spontaneously recovered. The mean time to retrieve a reward from the deep wells before MCAO was longer than that to retrieve a reward from the shallow wells. However, enhanced manual dexterity was observed 8 weeks after MCAO. Among the NHP stroke models induced by MCAO, Monkey A showed that the mean latency on each well and the motor function returned to baseline levels at 12 weeks after MCAO. These results indicated that hand motor recovery after stroke occurred past the 12-week time point, consistent with DTI data showing reorganization of the white matter fiber tract (Fig. 7). DTI scans were obtained at baseline (Fig. 7A), 8 weeks (Fig. 7B) and 12 weeks (Fig. 7C) after MCAO. Temporal changes in the contralateral and ipsilateral CST were observed, and discontinuity of the ipsilateral tract was apparent at 8 weeks after MCAO. At 12 weeks after MCAO, structural reorganization of the CST fibers was observed in the ipsilateral region, as evidenced by DTI-based fiber tractography. In addition, the longitudinal changes of the FA (Fig. 7D) and MD (Fig. 7E) were observed. The FA and MD is associated with pathological changes and neural injury following MCAO. A reduction in the FA values 

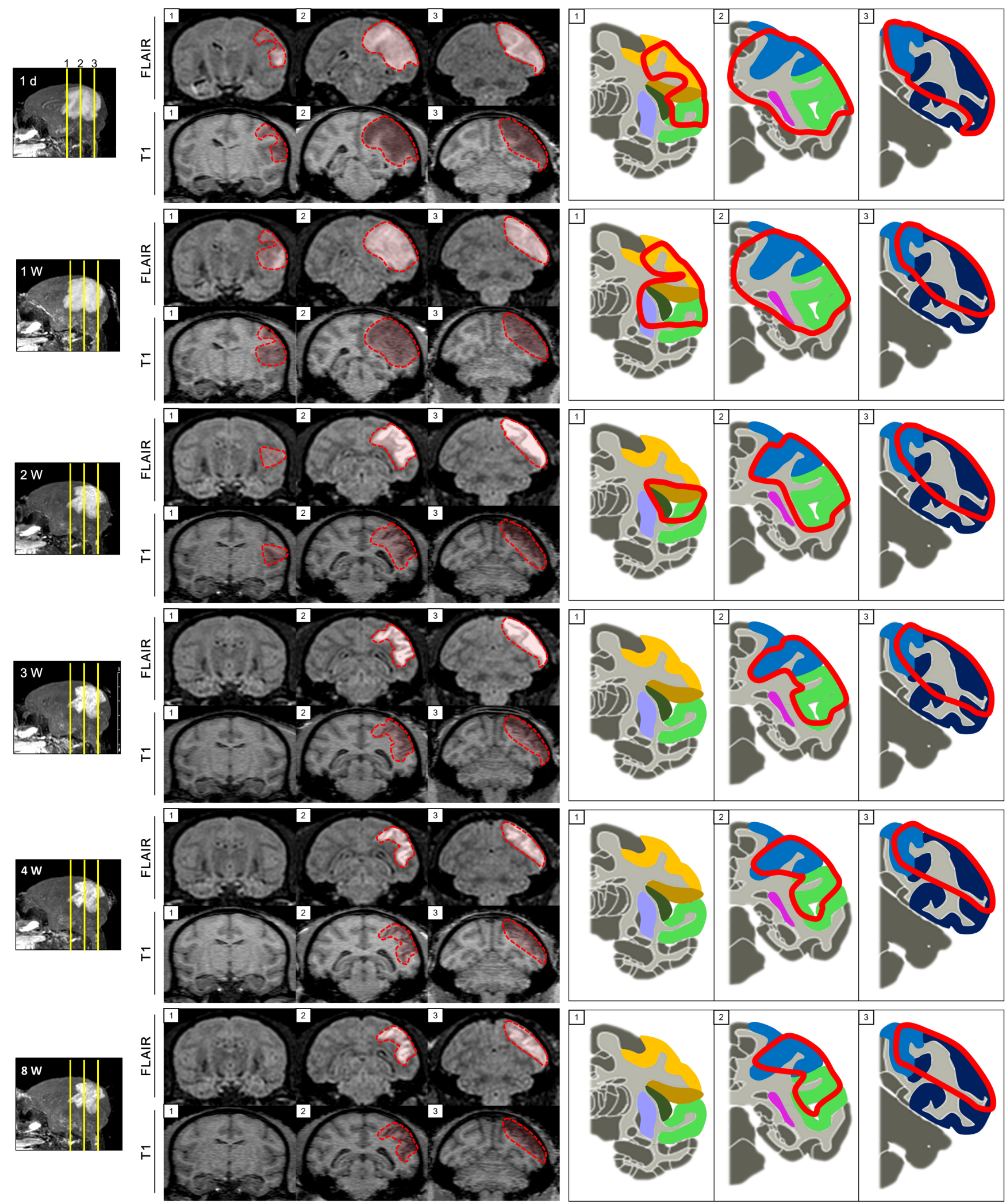

Fig. 5. Localization of cerebral ischemic infarct lesion. Cerebral ischemic infarct lesion was determined by FLAIR imaging and T1-weighted imaging. Representative coronal images from the rostral to caudal aspect of infarct core region were illustrated using the macaque brain atlas. Location of infarct lesion is indicated by red area. The shadow rectangles showed brain anatomical regions. 

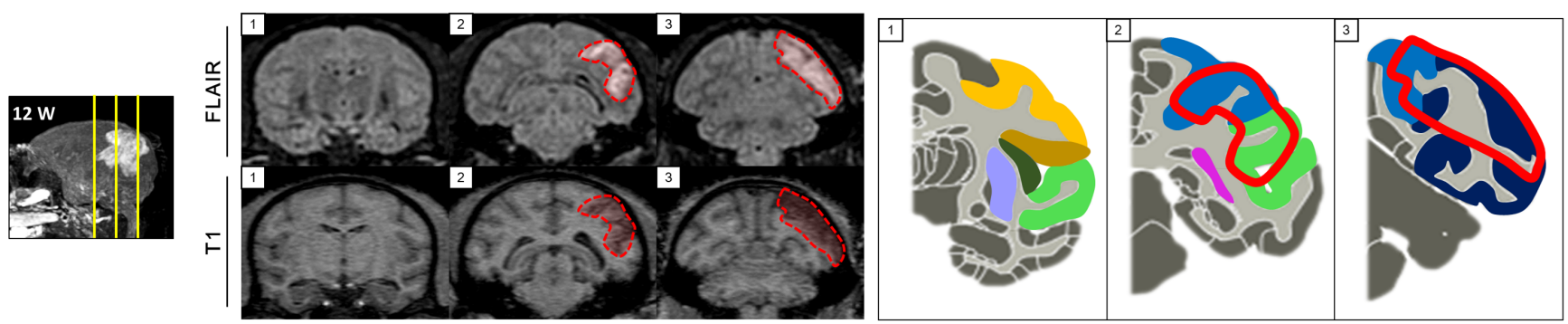

Primary somatosensory

Secondary somatosensory

Posterior parietal cortex

Temporal cortex (auditory)

Occipital cortex (visual)

Putamen

Caudate nucle

Fig. 5. Continued.

Table 1. Persistence of ischemic infarct lesion after MCAO

\begin{tabular}{|c|c|c|c|c|c|c|c|c|}
\hline \multirow{2}{*}{\multicolumn{2}{|c|}{ Anatomical area }} & \multicolumn{7}{|c|}{ Time after MCAO } \\
\hline & & ld & 1W & $2 W$ & $3 W$ & $4 W$ & $8 W$ & $12 W$ \\
\hline \multirow[t]{5}{*}{ Cortex } & Primary somatosensory & + & + & & & & & \\
\hline & Secondary somatosensory & + & + & + & & & & \\
\hline & Posterior parietal cortex & + & + & + & + & + & + & + \\
\hline & Temporal cortex (auditory) & + & + & + & + & + & + & + \\
\hline & Occipital cortex (visual) & + & + & + & + & + & + & + \\
\hline \multirow[t]{2}{*}{ Basal ganglia } & Putamen & & + & & & & & \\
\hline & Caudate nucleus & + & + & & & & & \\
\hline White matter & & + & + & + & + & + & + & + \\
\hline
\end{tabular}

A

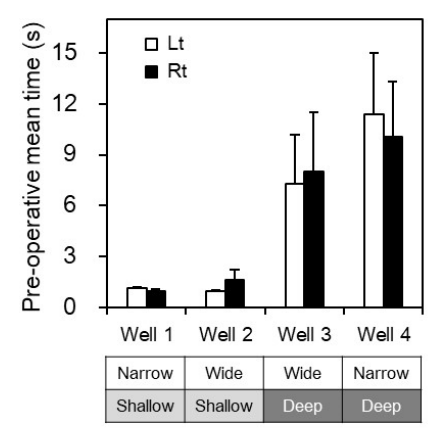

B

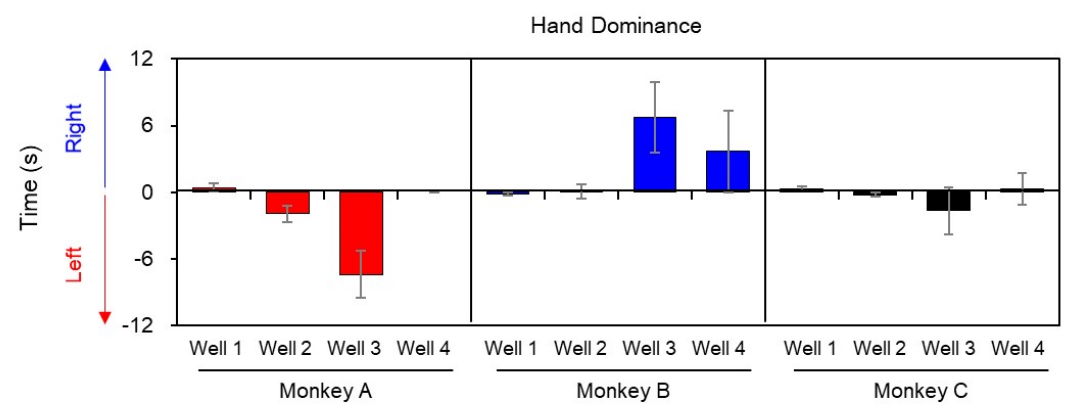

C
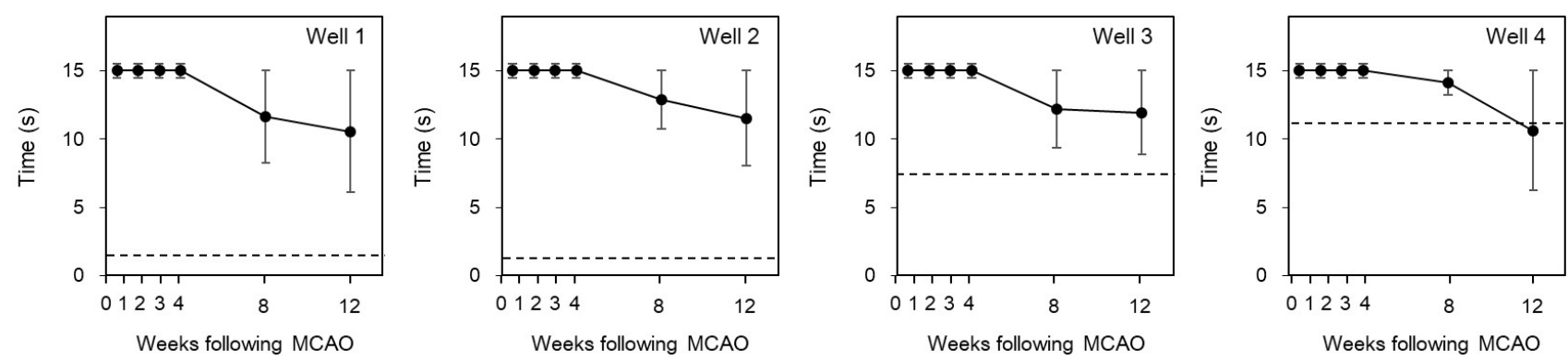

Fig. 6. Longitudinal assessment of fine motor recovery in the affected hand. (A) Comprehensive baseline assessment for evaluating hand function. Preoperative mean time to retrieve rewards from each well for both hands on the hand dexterity task. (B) Hand dominance was assessed by the average latency to retrieve a reward. (C) Quantitative analysis of impaired hand function, illustrating progressive improvement after MCAO to the level of baseline function. Enhanced retrieval performance was observed for each well of the hand dexterity task at 4 weeks after MCAO. Following middle cerebral artery occlusion (MCAO), the animal exhibited contralateral fine motor deficits of the hand. Data are represented as the mean $\pm S D, n=3$. 

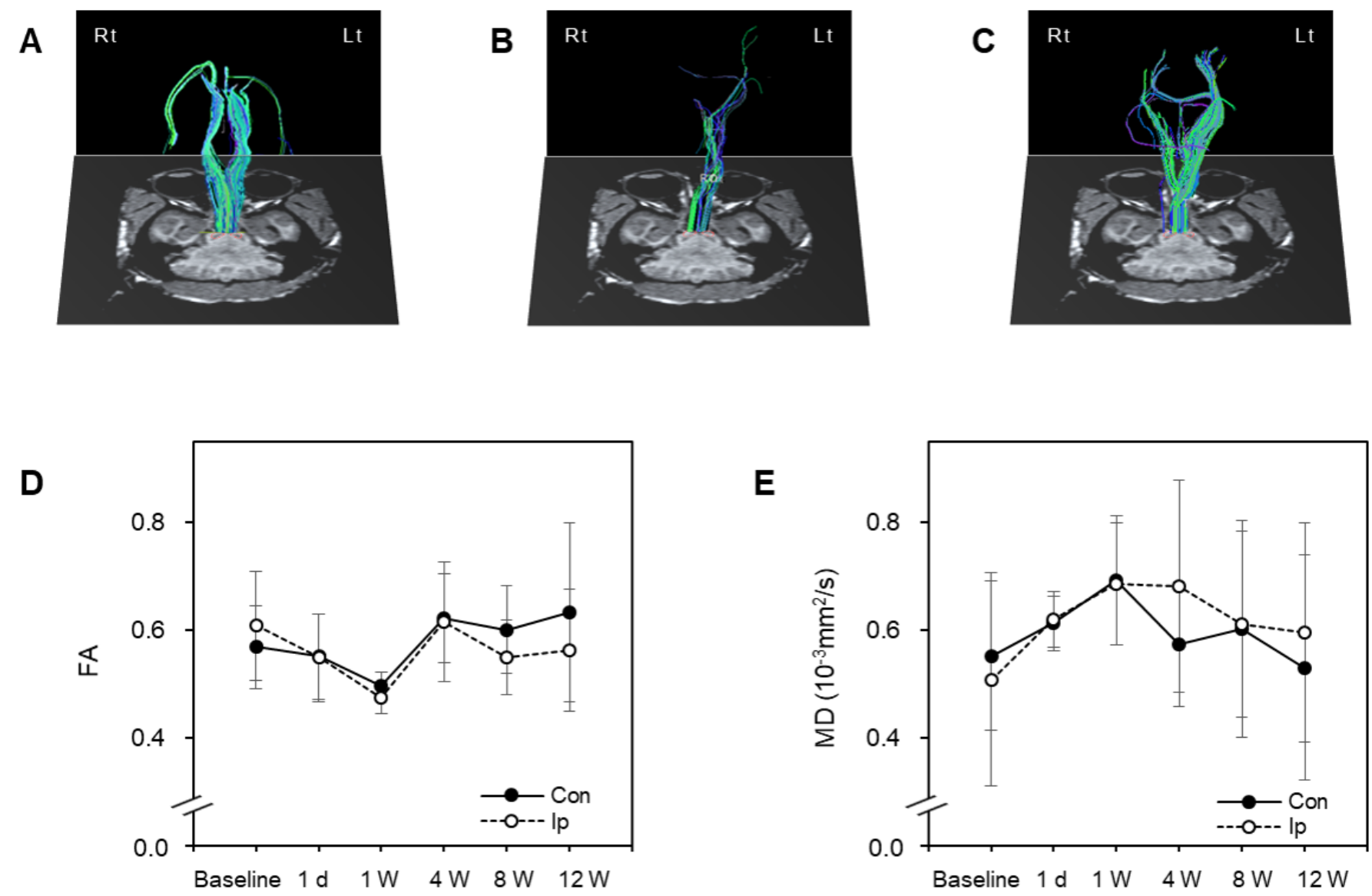

Fig. 7. Three-dimensional reconstruction of corticospinal tract (CST) from the non-human primate (NHP) stroke model on the axial sections of the DTI imaging and longitudinal changes of the DTI parameters. Representative CST fiber tractography at baseline (A), after 8 weeks (B) and after 12 weeks after MCAO (C). Temporal changes of DTI-based tractography after MCAO in contralateral (Left hemisphere) and ipsilateral (Right hemisphere) corticospinal tract (CST). While the fiber disruption of CST was detected in ipsilateral region at 8 weeks after MCAO, the structural reorganization was revealed at 12 weeks after MCAO. (D) The FA values of the ipsilateral CST (Right hemisphere) decreased during 1 week after MCAO compared to baseline, and recovered past the 12 -week time point. However, ipsilateral FA values of the CST was lower than contralateral side. (E) The MD values of the ipsilateral CST increased after MCAO during 4 weeks compared to baseline, and decreased pattern was observed at 8-12 weeks after MCAO. Lt, left hemisphere; Rt, right hemisphere; Con, contralateral CST; IP, ipsilateral CST; FA, fractional anisotropy; MD, mean diffusivity. Data from Monkey A are represented as the mean \pm standard error of the mean.

represents disintegration of the CST fibers, whereas increased MD values indicate vasogenic edema caused by MCAO. The FA values in the ipsilateral CST was lower than the baseline and contralateral side during the acute stroke phase (1 day and 1 week after MCAO), indicating the amount of damage in the CST due to MCAO. However, both contralateral and ipsilateral FA values improved from 4 to 12 weeks. The MD values in the ipsilateral and contralateral CST increased 4 weeks after MCAO due to vasogenic edema and then decreased as a result of axonal damage recovery. These results indicated that the reorganization and axonal recovery of the CST occurs post-stroke.

\section{Compensatory movement strategies}

At baseline, standard hand movement was observed during the motor task. However, compensatory behavior involving use of the non-affected hand to perform the task was observed after MCAO (Fig. 8A). Animals exhibited these altered hand movements and impaired dexterity after stroke while performing the HDT (Supplementary Video). A lower frequency of compensatory behavior and retrieval failure was exhibited in all wells of the HDT at $8 \sim 12$ weeks after MCAO, indicating spontaneous functional recovery (Fig. 8B).

A high prevalence of grip deficits and compensatory grip in the shallow wells was observed at 4 weeks after MCAO, and alternative and precision grip patterns were observed at $8 \sim 12$ weeks after MCAO (Fig. 8C). Most grip deficits were observed in the deep wells at 2 weeks, and recovery patterns were observed at 8 weeks after MCAO. This indicates that the extraneous movement of the 
A
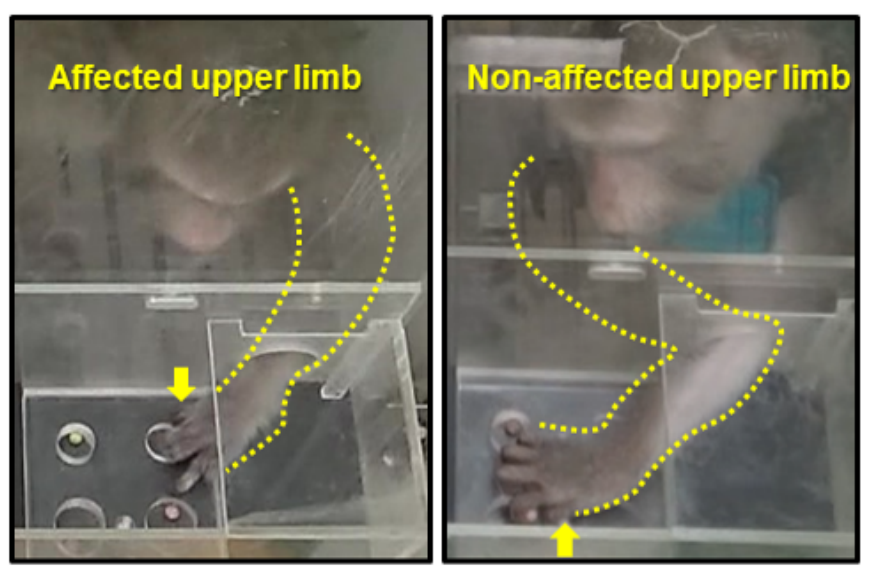

B

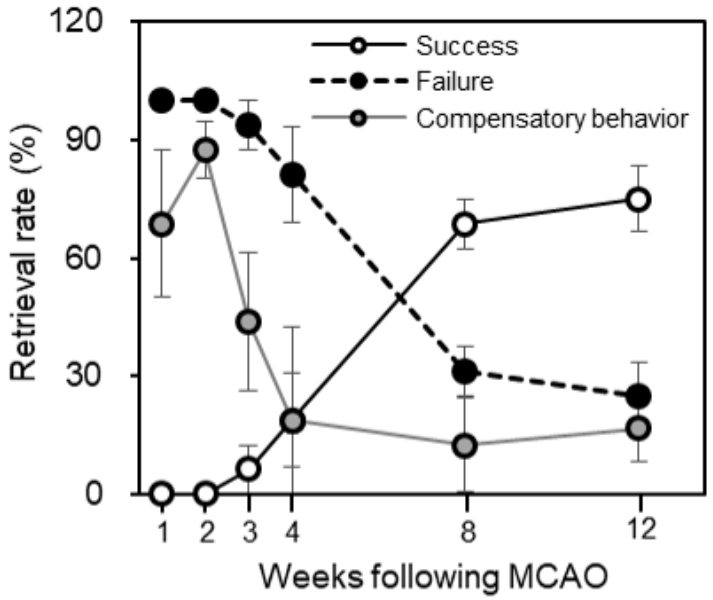

C

Well 1
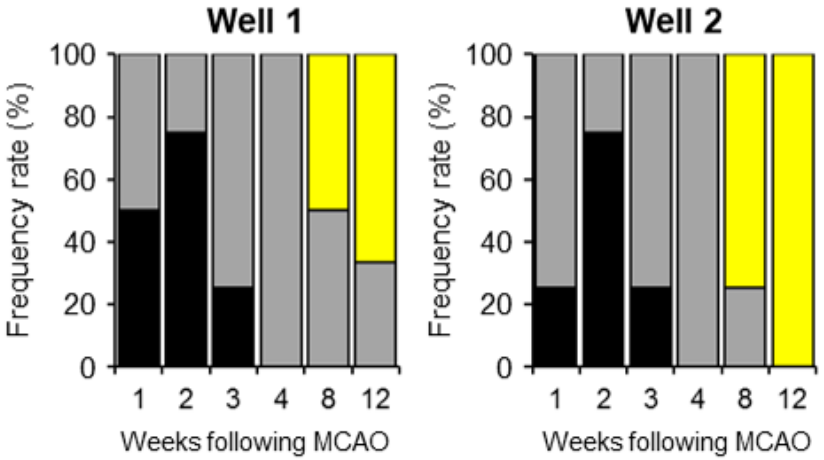

Well 3

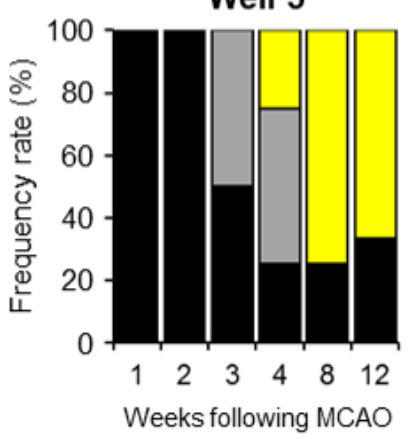

Well 4

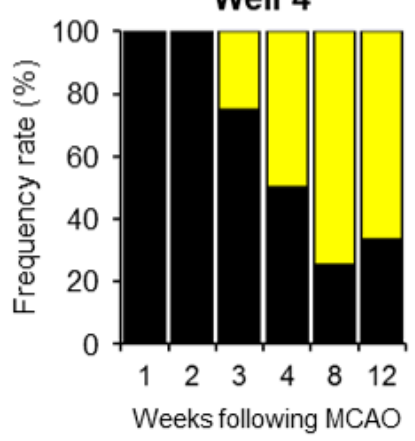

Failure $\square$ Compensatory behavior $\square$ Success

Fig. 8. Impaired dexterity and functional change in grip strategies. (A) Representative image demonstrating the standard position for the HDT (left panel), and compensatory behavior observed during the HDT (right panel). (B) Recovery curves of the success rate for retrieval after reperfusion. The reductions in compensatory behavior and retrieval failure were associated with increases in the success rate. (C) Grip pattern and deficits: failure (black), compensatory behavior (gray), and success (yellow).

non-affected hand was a consequence of motor compensation that occurred in response to unilateral impairment of the motor system following stroke.

\section{DISCUSSION}

The present study demonstrates the impact of cerebral ischemia on fine motor function in an NHP stroke model. We assessed the impairment of hand dexterity and examined motor recovery following stroke using the HDT, which was modified from Moore et al.'s HDT used to assess hand motor function in NHPs $[28,30]$. Although various assessment scales and devices to evaluate hand motor function in NHP models have been reported, most have been performed using chair restraint training [31-33]. The HDT used in this study adopted cage-based training that allowed it to be fully portable and cage-mountable for all NHP models. Imple- menting training within the animal's home cage reduces the efforts involved in chair training and decreases stress.

In this study, endovascular transient MCAO is used to investigate the mechanism underlying the spontaneous recovery after ischemic stroke. The permanent MCAO creates larger infarct lesion and induces irreversible neuronal damage [34]. However, transient MCAO model is useful to study neural repair process because the main target for stroke therapeutic approach is vessel recanalization to improve blood circulation to the reversible damaged ischemic tissue $[35,36]$. The optimal recanalization for acute ischemic stroke could improve clinical outcomes, whereas ischemia-reperfusion has the potential to induce subsequent damage to ischemic brain tissue [37]. Our main finding was that the brain structural changes, including the development and expansion of the infarct lesion, occur during the acute phase of stroke, and are accompanied by the loss of manual dexterity, which caused by reperfusion 
injury in response to oxidative stress, excitotoxicity, free radicals and mitochondrial dysfunction [38]. However, this neurological impairment improved progressively after stroke. This is consistent with clinical stroke study that reported the important part of neurological recovery occurring in the first three months following stroke [39]. In our study, we demonstrated the discontinuation and the reorganization of the CST fibers following MCAO, which were defined using fiber tractography and the two main parameters derived from the DTI dataset [40-42]. The axonal damage in the ipsilateral CST occurred during the acute phase and new CST fibers was observed past the 12-weeks point after onset, which suggests that post-stroke recovery results from neuroplasticity-related structural CST changes.

Consistent with these results, previous studies have reported the involvement of cerebral cortex lesions in the functional recovery of manual dexterity [27]. The impaired movement of the affected hand and the relative increase in reaction time in stroke patients have been reported to be correlated with the size of the brain lesions in the ipsilateral hemisphere $[43,44]$. In macaque monkeys, the manual dexterity deficit with flaccid paralysis induced by the motor cortex lesion exhibited functional recovery during the early post-recovery period, and was also accompanied by plastic responses, including enhanced activity and increased functional connectivity within the motor cortex $[45,46]$. In addition, the increased brain activity of the ipsilateral hemisphere in stroke patients has been reported in several functional MRI studies [47].

Interestingly, the frequency of compensatory movement was decreased, and was accompanied by restoration of manual dexterity in the chronic phase of stroke. Compensatory movement with the non-affected limb can emerge as a temporary response to and support the process of brain remodeling after stroke [48]. Nevertheless, even stroke patients with only mild impairment of the affected limb exhibit persistent compensatory movement with disuse of the affected side [49]. This was also observed in the present study, wherein the stroke NHP model relied on the non-affected hand instead of the affected hand. However, recent studies suggest that the use of compensatory movement strategies on the non-affected side activates the contralateral motor cortex and is correlated with post-stroke neural reorganization in acute stroke [50-52]. In a rodent stroke model, synaptic connectivity reorganization and synapse maturation were observed in the remaining neural circuits as a result of prior training in the non-affected forelimb [53]. These animal and clinical research results suggest that compensatory reliance on the non-affected side can promote brain plasticity and recovery after stroke. In macaque monkeys, the impaired precision grip that resulted from motor cortical infarcts was improved by alternative grip patterns, and was driven by daily training- induced compensation [54]. Similarly, such alternative movement is frequently observed in stroke patients, and could be developed via earlier rehabilitative intervention $[55,56]$. In our study, infarct lesion was observed primarily in the posterior parietal cortex, and the somatosensory cortex, in which ischemic injury occurred during the acute phase of stroke, exhibited spontaneous recovery. The parietal cortex has two functional zones, including the anterior and posterior part [57]. While the anterior parietal cortex, including the primary and secondary somatosensory area, has been considered as the somatic sensation and perception processing area, the posterior parietal cortex plays a role in integrating somatosensory information about limb position and controlling the guidance of movements [58]. We found that the parietal cortex injury induced by transient MCAO produced abnormal hand movements and compensatory behavior in the NHP model.

In this study, we describe the use of a behavioral assessment tool to provide an objective evaluation of fine motor function based on hand dexterity. Furthermore, the spontaneous recovery of fine motor function was confirmed in our NHP stroke model. Taken together, these findings will be useful in basic and translational research for quantitative assessment of impaired motor function following ischemic stroke. Despite animal-based pre-clinical models, our findings highlight the main characteristics of stroke progression, could provide a platform for further studies of a translational NHP stroke model, and could impact the diagnosis and evaluation of stroke patients. One limitation of our study is its small sample size. However, primary characteristics of NHP stroke model including the brain structural and pathophysiological change and progressive motor dysfunction were clearly demonstrated with expectation that NHP will mimic human results.

\section{ACKNOWLEDGEMENTS}

This research was supported by the Bio \& Medical Technology Development Program of the National Research Foundation of Korea (NRF) funded by the Korean government, (2016 M3A9B6902954, 2016M3A9B6903268, 2017M3A9G8084464, 2017M3C1B2085304), and the Korea Research Institute of Bioscience and Biotechnology Research Initiative Program (KGM4622013, KGM5282022, KGC1022012).

\section{REFERENCES}

1. Roth GA, Johnson C, Abajobir A, Abd-Allah F, Abera SF, Abyu G, Ahmed M, Aksut B, Alam T, Alam K, Alla F, AlvisGuzman N, Amrock S, Ansari H, Ärnlöv J, Asayesh H, Atey TM, Avila-Burgos L, Awasthi A, Banerjee A, Barac A, Bär- 
nighausen T, Barregard L, Bedi N, Belay Ketema E, Bennett D, Berhe G, Bhutta Z, Bitew S, Carapetis J, Carrero JJ, Malta DC, Castañeda-Orjuela CA, Castillo-Rivas J, Catalá-López F, Choi JY, Christensen H, Cirillo M, Cooper L Jr, Criqui M, Cundiff D, Damasceno A, Dandona L, Dandona R, Davletov K, Dharmaratne S, Dorairaj P, Dubey M, Ehrenkranz R, El Sayed Zaki M, Faraon EJA, Esteghamati A, Farid T, Farvid M, Feigin V, Ding EL, Fowkes G, Gebrehiwot T, Gillum R, Gold A, Gona P, Gupta R, Habtewold TD, Hafezi-Nejad N, Hailu T, Hailu GB, Hankey G, Hassen HY, Abate KH, Havmoeller R, Hay SI, Horino M, Hotez PJ, Jacobsen K, James S, Javanbakht M, Jeemon P, John D, Jonas J, Kalkonde Y, Karimkhani C, Kasaeian A, Khader Y, Khan A, Khang YH, Khera S, Khoja AT, Khubchandani J, Kim D, Kolte D, Kosen S, Krohn KJ, Kumar GA, Kwan GF, Lal DK, Larsson A, Linn S, Lopez A, Lotufo PA, El Razek HMA, Malekzadeh R, Mazidi M, Meier T, Meles KG, Mensah G, Meretoja A, Mezgebe H, Miller T, Mirrakhimov E, Mohammed S, Moran AE, Musa KI, Narula J, Neal B, Ngalesoni F, Nguyen G, Obermeyer CM, Owolabi M, Patton G, Pedro J, Qato D, Qorbani M, Rahimi K, Rai RK, Rawaf S, Ribeiro A, Safiri S, Salomon JA, Santos I, Santric Milicevic M, Sartorius B, Schutte A, Sepanlou S, Shaikh MA, Shin MJ, Shishehbor M, Shore H, Silva DAS, Sobngwi E, Stranges S, Swaminathan S, Tabarés-Seisdedos R, Tadele Atnafu N, Tesfay F, Thakur JS, Thrift A, Topor-Madry R, Truelsen T, Tyrovolas S, Ukwaja KN, Uthman O, Vasankari T, Vlassov V, Vollset SE, Wakayo T, Watkins D, Weintraub R, Werdecker A, Westerman R, Wiysonge CS, Wolfe C, Workicho A, Xu G, Yano Y, Yip P, Yonemoto N, Younis M, Yu C, Vos T, Naghavi M, Murray C (2017) Global, regional, and national burden of cardiovascular diseases for 10 causes, 1990 to 2015. J Am Coll Cardiol 70:1-25.

2. Howard G, Howard VJ, Katholi C, Oli MK, Huston S (2001) Decline in US stroke mortality: an analysis of temporal patterns by sex, race, and geographic region. Stroke 32:22132220.

3. Writing Group Members, Mozaffarian D, Benjamin EJ, Go AS, Arnett DK, Blaha MJ, Cushman M, Das SR, de Ferranti S, Després JP, Fullerton HJ, Howard VJ, Huffman MD, Isasi CR, Jiménez MC, Judd SE, Kissela BM, Lichtman JH, Lisabeth LD, Liu S, Mackey RH, Magid DJ, McGuire DK, Mohler ER 3rd, Moy CS, Muntner P, Mussolino ME, Nasir K, Neumar RW, Nichol G, Palaniappan L, Pandey DK, Reeves MJ, Rodriguez CJ, Rosamond W, Sorlie PD, Stein J, Towfighi A, Turan TN, Virani SS, Woo D, Yeh RW, Turner MB; American Heart Association Statistics Committee; Stroke Statistics Subcommittee (2016) Executive summary: heart disease and stroke statistics--2016 update: a report from the American Heart Association. Circulation 133:447-454.

4. Larpthaveesarp A, Gonzalez FF (2017) Transient middle cerebral artery occlusion model of neonatal stroke in p10 rats. J Vis $\operatorname{Exp}$ (122):54830.

5. Miller EL, Murray L, Richards L, Zorowitz RD, Bakas T, Clark P, Billinger SA; American Heart Association Council on Cardiovascular Nursing and the Stroke Council (2010) Comprehensive overview of nursing and interdisciplinary rehabilitation care of the stroke patient: a scientific statement from the American Heart Association. Stroke 41:2402-2448.

6. Minelli C, Gondim FA, Barreira AA, Dromerick AW (2009) Rehabilitation of the upper extremity and basic activities of daily living in the first month after ischemic stroke: an international cohort comparison study. Neurol Int 1:e4.

7. Bai YL, Hu YS, Wu Y, Zhu YL, Zhang B, Jiang CY, Sun LM, Fan WK (2014) Long-term three-stage rehabilitation intervention alleviates spasticity of the elbows, fingers, and plantar flexors and improves activities of daily living in ischemic stroke patients: a randomized, controlled trial. Neuroreport 25:9981005.

8. Jones TA (2017) Motor compensation and its effects on neural reorganization after stroke. Nat Rev Neurosci 18:267-280.

9. Van Ouwenaller C, Laplace PM, Chantraine A (1986) Painful shoulder in hemiplegia. Arch Phys Med Rehabil 67:23-26.

10. Park SY, Marasini S, Kim GH, Ku T, Choi C, Park MY, Kim EH, Lee YD, Suh-Kim H, Kim SS (2014) A method for generating a mouse model of stroke: evaluation of parameters for blood flow, behavior, and survival [corrected]. Exp Neurobiol 23:104-114.

11. Courtine G, Roy RR, Raven J, Hodgson J, McKay H, Yang H, Zhong H, Tuszynski MH, Edgerton VR (2005) Performance of locomotion and foot grasping following a unilateral thoracic corticospinal tract lesion in monkeys (Macaca mulatta). Brain 128(Pt 10):2338-2358.

12. Lemon RN (2008) Descending pathways in motor control. Annu Rev Neurosci 31:195-218.

13. Rimmele DL, Frey BM, Cheng B, Schulz R, Krawinkel LA, Bönstrup M, Braass H, Gerloff C, Thomalla G (2018) Association of extrapyramidal tracts' integrity with performance in fine motor skills after stroke. Stroke 49:2928-2932.

14. Courtine G, Bunge MB, Fawcett JW, Grossman RG, Kaas JH, Lemon R, Maier I, Martin J, Nudo RJ, Ramon-Cueto A, Rouiller EM, Schnell L, Wannier T, Schwab ME, Edgerton VR (2007) Can experiments in nonhuman primates expedite the translation of treatments for spinal cord injury in humans? Nat Med 13:561-566. 
15. Wu D, Chandra A, Chen J, Ding Y, Ji X (2018) Endovascular ischemic stroke models in nonhuman primates. Neurotherapeutics 15:146-155.

16. Zhao B, Shang G, Chen J, Geng X, Ye X, Xu G, Wang J, Zheng J, Li H, Akbary F, Li S, Lu J, Ling F, Ji X (2014) A more consistent intraluminal rhesus monkey model of ischemic stroke. Neural Regen Res 9:2087-2094.

17. Virley D, Hadingham SI, Roberts JC, Farnfield B, Elliott H, Whelan G, Golder J, David C, Parsons AA, Hunter AJ (2004) A new primate model of focal stroke: endothelin-1-induced middle cerebral artery occlusion and reperfusion in the common marmoset. J Cereb Blood Flow Metab 24:24-41.

18. Dai P, Huang H, Zhang L, He J, Zhao X, Yang F, Zhao N, Yang J, Ge L, Lin Y, Yu H, Wang J (2017) A pilot study on transient ischemic stroke induced with endothelin-1 in the rhesus monkeys. Sci Rep 7:45097.

19. McEntire CR, Choudhury GR, Torres A, Steinberg GK, Redmond DE Jr, Daadi MM (2016) Impaired arm function and finger dexterity in a nonhuman primate model of stroke: motor and cognitive assessments. Stroke 47:1109-1116.

20. Moore TL, Killiany RJ, Pessina MA, Moss MB, Finklestein SP, Rosene DL (2012) Recovery from ischemia in the middleaged brain: a nonhuman primate model. Neurobiol Aging 33:619.e9-619.e24.

21. Yeo HG, Lee Y, Jeon CY, Jeong KJ, Jin YB, Kang P, Kim SU, Kim JS, Huh JW, Kim YH, Sim BW, Song BS, Park YH, Hong Y, Lee SR, Chang KT (2015) Characterization of cerebral damage in a monkey model of Alzheimer's disease induced by intracerebroventricular injection of streptozotocin. J Alzheimers Dis 46:989-1005.

22. Park J, Seo J, Won J, Yeo HG, Ahn YJ, Kim K, Jin YB, Koo BS, Lim KS, Jeong KJ, Kang P, Lee HY, Baek SH, Jeon CY, Hong JJ, Huh JW, Kim YH, Park SJ, Kim SU, Lee DS, Lee SR, Lee Y (2019) Abnormal mitochondria in a non-human primate model of MPTP-induced Parkinson's disease: Drp1 and CDK5/p25 signaling. Exp Neurobiol 28:414-424.

23. Jeong HS, Lee SR, Kim JE, Lyoo IK, Yoon S, Namgung E, Chang KT, Kim BS, Yang S, Im JJ, Jeon S, Kang I, Ma J, Chung YA, Lim SM (2018) Brain structural changes in cynomolgus monkeys administered with 1-methyl-4-phenyl-1,2,3,6tetrahydropyridine: a longitudinal voxel-based morphometry and diffusion tensor imaging study. PLoS One 13:e0189804.

24. Yi KS, Choi CH, Lee SR, Lee HJ, Lee Y, Jeong KJ, Hwang J, Chang KT, Cha SH (2017) Sustained diffusion reversal with in-bore reperfusion in monkey stroke models: confirmed by prospective magnetic resonance imaging. J Cereb Blood Flow Metab 37:2002-2012.
25. Yeo HG, Hong JJ, Lee Y, Yi KS, Jeon CY, Park J, Won J, Seo J, Ahn YJ, Kim K, Baek SH, Hwang EH, Kim G, Jin YB, Jeong KJ, Koo BS, Kang P, Lim KS, Kim SU, Huh JW, Kim YH, Son Y, Kim JS, Choi CH, Cha SH, Lee SR (2019) Increased CD68/ TGF $\beta$ co-expressing microglia/ macrophages after transient middle cerebral artery occlusion in rhesus monkeys. Exp Neurobiol 28:458-473.

26. Paxinos G, Huang XF, Toga AW (2000) The rhesus monkey brain in stereotaxic coordinates. Academic Press, San Diego, CA.

27. Moore TL, Pessina MA, Finklestein SP, Killiany RJ, Bowley B, Benowitz L, Rosene DL (2016) Inosine enhances recovery of grasp following cortical injury to the primary motor cortex of the rhesus monkey. Restor Neurol Neurosci 34:827-848.

28. Moore TL, Killiany RJ, Pessina MA, Moss MB, Rosene DL (2010) Assessment of motor function of the hand in aged rhesus monkeys. Somatosens Mot Res 27:121-130.

29. Chatagny P, Badoud S, Kaeser M, Gindrat AD, Savidan J, Fregosi M, Moret V, Roulin C, Schmidlin E, Rouiller EM (2013) Distinction between hand dominance and hand preference in primates: a behavioral investigation of manual dexterity in nonhuman primates (macaques) and human subjects. Brain Behav 3:575-595.

30. Moore TL, Pessina MA, Finklestein SP, Kramer BC, Killiany RJ, Rosene DL (2013) Recovery of fine motor performance after ischemic damage to motor cortex is facilitated by cell therapy in the rhesus monkey. Somatosens Mot Res 30:185196.

31. Schmidlin E, Kaeser M, Gindrat AD, Savidan J, Chatagny P, Badoud S, Hamadjida A, Beaud ML, Wannier T, Belhaj-Saif A, Rouiller EM (2011) Behavioral assessment of manual dexterity in non-human primates. JVis Exp (57):3258.

32. Hoogewoud F, Hamadjida A, Wyss AF, Mir A, Schwab ME, Belhaj-Saif A, Rouiller EM (2013) Comparison of functional recovery of manual dexterity after unilateral spinal cord lesion or motor cortex lesion in adult macaque monkeys. Front Neurol 4:101.

33. Chao ZC, Sawada M, Isa T, Nishimura Y (2019) Dynamic reorganization of motor networks during recovery from partial spinal cord injury in monkeys. Cereb Cortex 29:3059-3073.

34. McBride DW, Zhang JH (2017) Precision stroke animal models: the permanent MCAO model should be the primary model, not transient MCAO. Transl Stroke Res. doi: 10.1007/ s12975-017-0554-2.

35. Nour M, Scalzo F, Liebeskind DS (2013) Ischemia-reperfusion injury in stroke. Interv Neurol 1:185-199.

36. Pan J, Konstas AA, Bateman B, Ortolano GA, Pile-Spellman 
J (2007) Reperfusion injury following cerebral ischemia: pathophysiology, MR imaging, and potential therapies. Neuroradiology 49:93-102.

37. de Vries DK, Kortekaas KA, Tsikas D, Wijermars LG, van Noorden CJ, Suchy MT, Cobbaert CM, Klautz RJ, Schaapherder AF, Lindeman JH (2013) Oxidative damage in clinical ischemia/reperfusion injury: a reappraisal. Antioxid Redox Signal 19:535-545.

38. Zweier JL, Talukder MA (2006) The role of oxidants and free radicals in reperfusion injury. Cardiovasc Res 70:181-190.

39. Hatem SM, Saussez G, Della Faille M, Prist V, Zhang X, Dispa D, Bleyenheuft Y (2016) Rehabilitation of motor function after stroke: a multiple systematic review focused on techniques to stimulate upper extremity recovery. Front Hum Neurosci 10:442.

40. Bleyenheuft Y, Grandin CB, Cosnard G, Olivier E, Thonnard JL (2007) Corticospinal dysgenesis and upper-limb deficits in congenital hemiplegia: a diffusion tensor imaging study. Pediatrics 120:e1502-e1511.

41. Lazaridou A, Astrakas L, Mintzopoulos D, Khanicheh A, Singhal AB, Moskowitz MA, Rosen B, Tzika AA (2013) Diffusion tensor and volumetric magnetic resonance imaging using an MR-compatible hand-induced robotic device suggests training-induced neuroplasticity in patients with chronic stroke. Int J Mol Med 32:995-1000.

42. Stadlbauer A, Nimsky C, Gruber S, Moser E, Hammen T, Engelhorn T, Buchfelder M, Ganslandt O (2007) Changes in fiber integrity, diffusivity, and metabolism of the pyramidal tract adjacent to gliomas: a quantitative diffusion tensor fiber tracking and MR spectroscopic imaging study. AJNR Am J Neuroradiol 28:462-469.

43. Foltys H, Krings T, Meister IG, Sparing R, Boroojerdi B, Thron A, Töpper R (2003) Motor representation in patients rapidly recovering after stroke: a functional magnetic resonance imaging and transcranial magnetic stimulation study. Clin Neurophysiol 114:2404-2415.

44. Johansen-Berg H, Rushworth MF, Bogdanovic MD, Kischka U, Wimalaratna S, Matthews PM (2002) The role of ipsilateral premotor cortex in hand movement after stroke. Proc Natl Acad Sci U S A 99:14518-14523.

45. Murata Y, Higo N, Hayashi T, Nishimura Y, Sugiyama Y, Oishi T, Tsukada H, Isa T, Onoe H (2015) Temporal plasticity involved in recovery from manual dexterity deficit after motor cortex lesion in macaque monkeys. J Neurosci 35:84-95.

46. Savidan J, Kaeser M, Belhaj-Saif A, Schmidlin E, Rouiller EM (2017) Role of primary motor cortex in the control of manual dexterity assessed via sequential bilateral lesion in the adult macaque monkey: a case study. Neuroscience 357:303-324.

47. Rehme AK, Fink GR, von Cramon DY, Grefkes C (2011) The role of the contralesional motor cortex for motor recovery in the early days after stroke assessed with longitudinal FMRI. Cereb Cortex 21:756-768.

48. Nakayama H, Jørgensen HS, Raaschou HO, Olsen TS (1994) Compensation in recovery of upper extremity function after stroke: the Copenhagen stroke study. Arch Phys Med Rehabil 75:852-857.

49. Dromerick AW, Lang CE, Birkenmeier R, Hahn MG, Sahrmann SA, Edwards DF (2006) Relationships between upperlimb functional limitation and self-reported disability 3 months after stroke. J Rehabil Res Dev 43:401-408.

50. Jones TA, Jefferson SC (2011) Reflections of experienceexpectant development in repair of the adult damaged brain. Dev Psychobiol 53:466-475.

51. Jones TA, Allred RP, Jefferson SC, Kerr AL, Woodie DA, Cheng SY, Adkins DL (2013) Motor system plasticity in stroke models: intrinsically use-dependent, unreliably useful. Stroke 44(6 Suppl 1):S104-S106.

52. Kim SY, Allred RP, Adkins DL, Tennant KA, Donlan NA, Kleim JA, Jones TA (2015) Experience with the "good" limb induces aberrant synaptic plasticity in the perilesion cortex after stroke. J Neurosci 35:8604-8610.

53. Whishaw IQ (2000) Loss of the innate cortical engram for action patterns used in skilled reaching and the development of behavioral compensation following motor cortex lesions in the rat. Neuropharmacology 39:788-805.

54. Murata Y, Higo N, Oishi T, Yamashita A, Matsuda K, Hayashi $M$, Yamane S (2008) Effects of motor training on the recovery of manual dexterity after primary motor cortex lesion in macaque monkeys. J Neurophysiol 99:773-786.

55. Han CE, Kim S, Chen S, Lai YH, Lee JY, Osu R, Winstein CJ, Schweighofer N (2013) Quantifying arm nonuse in individuals poststroke. Neurorehabil Neural Repair 27:439-447.

56. Raghavan P, Santello M, Gordon AM, Krakauer JW (2010) Compensatory motor control after stroke: an alternative joint strategy for object-dependent shaping of hand posture. J Neurophysiol 103:3034-3043.

57. Goldberg ME (2001) Parietal lobe. In: International encyclopedia of the social \& behavioral sciences (Smelser NJ, Baltes PB, eds), pp 11051-11054. Elsevier, Amsterdam.

58. Tuite PJ, Konczak J (2010) Cortical sensory dysfunction and the parietal lobe. In: Encyclopedia of movement disorders (Kompoliti K, Verhagen Metman V, eds), pp 254-257. Academic Press, Amsterdam. 